\title{
Aligned unidirectional PLA/bacterial cellulose nanocomposite fibre reinforced PDLLA composites
}

Jonny J. Blaker ${ }^{\mathrm{a}^{*}}$, Koon-Yang Lee ${ }^{\mathrm{b}}$, Matthew Walters ${ }^{\mathrm{c}}$, Marc Drouet ${ }^{\mathrm{c}}$, Alexander Bismarck $^{\mathrm{c}, \mathrm{d}}$

${ }^{a}$ Materials Science Centre, School of Materials, The University of Manchester, Grosvenor Street, M1 7HS, Manchester, United Kingdom

${ }^{\mathrm{b}}$ Department of Chemical Engineering, University College London, Torrington Place, WC1E 7JE, London, United Kingdom

c Polymer and Composite Engineering (PaCE) Group, Institute of Materials Chemistry and Research, Faculty of Chemistry, University of Vienna, Währinger Strasse 42, A-1090 Vienna, Austria and ${ }^{\mathrm{d}}$ Polymer and Composite Engineering (PaCE) Group, Department of Chemical Engineering, Imperial College London, South Kensington Campus, London SW7 2AZ, United Kingdom

* Corresponding author. E-mail: jonny.blaker@manchester.ac.uk Tel: +44 (0)161 30 63587.

\begin{abstract}
In an effort to enhance the properties of polylactide (PLA), we have developed meltspinning techniques to produce both PLA/nanocellulose composite fibres, and a method akin to layered filament winding followed by compression moulding to produce self-reinforced PLA/nanocellulose composites. Poly(L-lactide) (PLLA) fibres were filled with 2 wt.\% neat and modified bacterial cellulose (BC) in an effort to improve the tensile properties over neat PLA fibres. BC increased the viscosity of the polymer melt and reduced the draw-ratio of the fibres, resulting in increased fibre diameters. Nonetheless, strain induced chain orientation due to melt spinning led to PLLA fibres with enhanced tensile modulus (6 GPa) and strength (127 MPa), over monolithic PLLA, previously measured at $1.3 \mathrm{GPa}$ and $61 \mathrm{MPa}$, respectively. The presence of BC also enhanced the nucleation and growth of crystals in PLA. We further produced PLA fibres with 7 wt.\% cellulose nanocrystals (CNC), which is higher than the percolation threshold (equivalent to 6 vol.\%). These fibres were spun in multiple, alternating controlled layers onto spools, and subsequently compression moulded to produce unidirectional self-reinforced PLA composites consisting of 60
\end{abstract}


vol.\% PLLA fibres reinforced with 7 wt.\% CNC in a matrix of amorphous PDLLA, which itself contained $7 \mathrm{wt} \%$ of CNC. We observed improvements in viscoelastic properties of up to $175 \%$ in terms of storage moduli in bending. Furthermore, strains to failure for PLLA fibre reinforced PDLLA were recorded at $17 \%$.

\section{Keywords}

PLA, Bacterial Cellulose, Nanocomposite, Self-reinforced Polymer, Melt-Spinning

\section{Introduction}

The development of self-reinforced thermoplastic polymer composites, in which both the reinforcing and the continuous phases are polymers with the same chemical composition provides several benefits, including the potential for recycling at the end of product life, as well as inherent compatibility between matrix and reinforcement phases. The processing of PLA into fibres facilitates strain induced polymer chain orientation and hence crystallinity in the axial direction of the fibres, leading to enhanced mechanical and thermal properties, as described further below [1-6]. Singlepolymer composites based on polyethylene (PE) fibres in PE matrices have been studied since 1975 [7]. Such self-reinforced polymer composites are commonly produced either by taking advantage of different melt (or flowing) temperatures of polymers with different thermal properties, or by fusing the exterior of fibres. Selfreinforced PLA has for example been produced via a film stacking method whereby amorphous PLA sheets were inserted into layers of PLLA fibres and subsequently compression moulded [8]. Jia produced unidirectional (UD) self-reinforced PLA composites via film/yarn stacking, using approximately 21 vol.\% fibre reinforcement and reported a tensile strength of $48 \mathrm{MPa}$, Young's modulus of $3.29 \mathrm{GPa}$ and 4-6 \% strain to failure [9]. PLA fibres have been formed by melt-spinning with various draw ratios and processing conditions by several authors [1-6,10-12]. High modulus (5.5 $\mathrm{GPa}$ ) and strength (320 MPa) PLLA fibres with diameters down to $11 \mu \mathrm{m}$ have been produced by a variation on melt-spinning using a compressed air-drag method to achieve spinning rates of up to $5000 \mathrm{~m} \mathrm{~min}^{-1}$ [3]. In other work, as spun PLLA fibres with diameters $270 \mu \mathrm{m}$ were further hot drawn to obtain fibres with $150 \mu \mathrm{m}$ which had much improved properties; i.e. the strength and modulus increased from $95 \mathrm{MPa}$ and 2.2 GPa up to $600 \mathrm{MPa}$ and 5.4 GPa, respectively [4]. Shrinkage resistance has also shown to improve with increasing fibre crystallinity [3,5]. Moreover, it is 
possible to fill PLA fibres with nanosized reinforcements, such as clay [13], carbon nanotubes [14] and cellulose nanowhiskers [15]. Due to their high specific surface areas and size, these nanoparticles can act as nucleation sites for the crystallization of the polymer matrix phase [16-19]. In this context, nanocellulose produced by bacteria $[20,21]$, otherwise known as bacterial cellulose (BC), is advantageous as a filler in PLA, due to its green credentials, it is inherently nanosized, and free of wax, lignin, hemicellulose and pectin, which are common in plant-based cellulosic materials [22]. Further, BC is highly crystalline, with a degree of crystallinity of about $90 \%$ [23], and a Young's modulus of $114 \mathrm{GPa}$ [24] and a tensile strength of potentially up to 6000 $\mathrm{MPa}$ [25]. Bacterial/plant-based cellulose can further be hydrolysed to form cellulose nanowhiskers (CNW), also termed cellulose nanocrystals (CNC). PLA/cellulose nanowhisker (CNW) filled with 1-3 wt.\% CNW (derived from microcrystalline cellulose) composite fibres have been produced, however, these fibres showed no significant influence on mechanical properties was observed [15]. The presence of CNW in PLA has been reported to reduce the shrinkage of PLA fibres, and improve their creep resistance due to the CNW impeding chain mobility [15]. Higher draw ratios lead to increased strain induced polymer chain orientation. Multi-wall carbon nanotubes have been used to filled PLA fibres with draw ratios up to 36.5. However, with more than 5 wt.\% nanotube loadings drawability was reported to decrease [14]. PLLA fibres have been melt-spun to diameters $11.2 \mu \mathrm{m}$ and were later coated with CNW derived from hydrolysed cotton in polyvinyl acetate (PVAc) for tissue engineering applications [26]. These PLLA fibres were produced by melt-spinning from a $2 \mathrm{~mm}$ diameter die, at a speed of $400 \mathrm{~m} \mathrm{~min}^{-1}$. The high draw ratio resulted in neat PLLA fibres with a modulus and strength of $4.9 \mathrm{GPa}$ and $208 \mathrm{MPa}$, coating with CNW containing PVAc resulted in improvements of up to $45 \%$ in terms of tensile modulus [26]. PLA/CNW fibres of diameters as low as $300 \mathrm{~nm}$ have been produced by electrospinning [27], whilst no mechanical data were provided, the CNW were shown to act as heterogeneous nucleating sites for PLA crystallisation, exhibiting reduced cold crystallisation onset temperatures from $69^{\circ} \mathrm{C}$ to $65^{\circ} \mathrm{C}$ in the presence of 2.5 wt. \% CNW.

Our motivation for this work was to produce PLA/BC composites fibres with a constant loading fraction of $2 \mathrm{wt} . \% \mathrm{BC}$ and to study the effect of BC surface-only modification on their properties. These PLA/BC composite fibres were used to 
manufacture all-PLA self-reinforced unidirectional composites. Such all-PLA composites might find applications in non-structural automotive parts, consumer products and structural packaging, and enable downstream recycling of all material components by remoulding, without requiring separation. We have previously produced BC reinforced PLA composites and shown that surface-only BC modification via organic acid esterification rendered the otherwise hydrophilic BC hydrophobic [28]. This modification was shown reduce the contact angle of PLLA droplets on BC nanofibrils, and hence improve the interfacial adhesion between BC and PLA, and resulting in improved tensile and viscoelastic properties in the composites [28].

Further, it is known that loadings of 6 vol.\% (equivalent to $7 \mathrm{wt} . \%$ ) cellulose nanocrystals in PLA can form percolating networks [16], in this work, we report a process based on filament winding and post consolidation, that allows for the production of unidirectional all-PLA composites, with CNC present in the PLLA reinforcing fibres as well as the amorphous PDLLA matrix, at percolated network thresholds.

\section{Materials and Methods}

\subsection{Materials}

PLLA was purchased from Biomer (L9000, Mw $\geq 150 \mathrm{~kg} \mathrm{~mol}^{-1}$, D-content $\sim 1.5 \%$ ) and was used as the matrix for the polymer fibres. Amorphous PDLLA was obtained from Nature Works (4060D) and was ultimately used as the matrix for PLLA fibre reinforced PLA composites. 1,4-Dioxane (Sigma-Aldrich, ACS Reagent, $\geq 99 \%$ purity) was used as solvent for PLA. Pyridine (analaR NORAMPUR, $\geq 99.7 \%$ purity), methanol (GPR, $\geq 99 \%$ purity), ethanol (GPR, $\geq 99 \%$ purity) were purchased from VWR. $p$-Toluenesulfonyl chloride (Aldrich, $\geq 99 \%$ purity) was purchased from Sigma-Aldrich. Sodium hydroxide (purum grade, pellets) was purchased from Acros Organics. All materials were used as received without further purification. Polyimide (Kapton $\left.{ }^{\circledR}\right)$ tape and film were obtained from DuPont. Bacterial cellulose nanofibrils (BC) were extracted from commercially available nata-de-coco (CHAOKOH coconut gel in syrup, Ampol Food Processing Ltd., Nakorn Pathom, Thailand). $\mathrm{H}_{2} \mathrm{SO}_{4}$ was used to hydrolyse the $\mathrm{BC}$ to cellulose nanocrystals (CNC). 
2.2 Extraction and surface-only modification of BC via organic acid esterification $\mathrm{BC}$ was extracted from nata-de-coco, rinsed, blended, homogenized, purified to remove any remaining microorganisms and soluble polysaccharides [29], followed by multiple centrifugation, rinsing and homogenization cycles to return the aqueous dispersion of $\mathrm{BC}$ to neutral $\mathrm{pH}$, according to our previous work $[28,30]$. $\mathrm{BC}$ was then modified via an organic acid esterification procedure, described in detail [28]. Briefly, dispersions of $\mathrm{BC}$ were solvent exchanged into pyridine from water through methanol and esterified with either hexanoic acid or dodecanoic acid in the presence or $p$ toluenesulonyl chloride. After the reaction, the reaction medium was quenched with ethanol and the modified cellulose product rinsed several times with ethanol and solvent exchanged into dimethyl carbonate [28]. Neat and modified BC were dispersed in water and dimethyl carbonate respectively at a concentration of $0.4 \%$ (g $\mathrm{mL}^{-1}$ ), flash frozen in Petri dishes by immersion in liquid nitrogen and subsequently freeze-dried (Edwards Modulyo freeze dryer, UK). BC functionalised with hexanoic and dodecanoic acid are here termed $\mathrm{C}_{6}-\mathrm{BC}$ and $\mathrm{C}_{12}-\mathrm{BC}$, respectively.

\subsection{Hydrolysis of $\mathrm{BC}$ to obtain $\mathrm{CNCs}$}

Acid hydrolysis of BC (previously dispersed in water) was carried out by stirring BC continuously in $60 \%(\mathrm{w} / \mathrm{w}) \mathrm{H}_{2} \mathrm{SO}_{4}$ at $60^{\circ} \mathrm{C}$ for 1 hour [31] to produce CNCs with average dimensions $25 \mathrm{~nm}$ x $280 \mathrm{~nm}$. Specifically, the amount of $\mathrm{H}_{2} \mathrm{SO}_{4}$ solution used for the hydrolysis was based on the dry weight of cellulose $(800 \mathrm{ml}$ solution per $1 \mathrm{~g}$ dry weight cellulose). After hydrolysis, the suspension was centrifuged and diluted several times, until $\mathrm{pH}$ neutral. The CNCs were solvent exchanged from deionised water $\left(\mathrm{dH}_{2} \mathrm{O}\right)$ into dioxane through acetone (3 times per solvent exchange, with centrifugation and homogenization steps in between) and a sample taken in order to ascertain their wet:dry ratio for the production of PLA/CNC composite feedstock, described below.

\subsection{Preparation of (composite) spheres as masterbatch for extrusion/melt-spinning} In this work, thermally induced phase separation (TIPS) [32] was used to produce composite spheres, as detailed in our previous work [28]. The method enables the homogeneous dispersion of large quantities of dry BC, modified-BC, as well as CNCs in a polymer melt using conventional extrusion processes at later stages. Five types of composite feedstock were made: PLLA + 2 wt. \% BC; PLLA + 2 wt.\% $\mathrm{C}_{6}$-BC; PLLA 
+2 wt.\% $\mathrm{C}_{12}$-BC; PLLA +7 wt.\% CNC; PDLLA containing 7 wt.\% CNC. For the production of $\mathrm{CNC}$ containing composite spheres, the concentration of CNCs was adjusted to the correct amount relative to PLA in 1,4-dioxane and the solution homogenised at 20,000 rpm to disperse them in solvent prior to subsequent freezing in liquid nitrogen and freeze-drying [28]. Neat PLLA and PDLLA spheres were also produced as feedstock [28]. Briefly, the resulting mixtures were poured separately into individual $50 \mathrm{ml}$ syringes and added drop wise into a bath of liquid nitrogen to rapidly induce phase separation. The precipitates were collected in a $500 \mathrm{ml}$ round bottom flask and subsequently freeze-dried to yield porous neat polymer and composite spheres, measuring circa $2-4 \mathrm{~mm}$ in diameter, suitably small to enter the extruder feed port.

\subsection{Extrusion and melt-spinning of PLA fibres}

The neat polymer and composite spheres were fed into a twin-screw micro-extruder ( $5 \mathrm{~cm}^{3}$ micro-extruder, DSM, The Netherlands) kept at $180{ }^{\circ} \mathrm{C}$ and a screw rotational speed of $10 \mathrm{rpm}$. After the addition of all the spheres, the screw speed was increased to $40 \mathrm{rpm}$ for $30 \mathrm{~min}$ to promote mixing of $\mathrm{BC} / \mathrm{CNCs}$ in the molten or flowing polymer. Finally, the polymer was extruded at a screw rotation speed of $10 \mathrm{rpm}$. The extrudate was taken from the exit gate (die diameter $=1 \mathrm{~mm}$ ) and linked directly to the fibre spinning apparatus (DSM XPlore, The Netherlands); a start-up torque of 75 $\mathrm{mN}$ was used and the fibres spun at a speed of $100 \mathrm{~m} \mathrm{~min}^{-1}$ directly onto cardboard spools. The spinning speed was maintained constant for all produced fibres. All fibre types produced are summarised in Table 1.

\subsection{Physical and thermal properties of the PLA fibres}

Scanning electron microscopy (SEM) was used to assess the morphology and diameters of the fibres (analysed using Image-J). The glass transition temperature, crystallisation and melting behaviour of neat PLA and composite fibres were determined using differential scanning calorimetry (DSC Q2000, TA Instruments, UK) in a He atmosphere. DSC was used to assess the crystallinity of PLLA, both first and second heating curves were analysed to assess the influence of drawing ratio on crystallinity and the capacity for nanocellulose to act as nucleation sites for PLA crystallisation. A heating-cooling-heating regime was used as follows, from room temperature (RT) to $200{ }^{\circ} \mathrm{C}$ at $10{ }^{\circ} \mathrm{C} \mathrm{min}-1$, held at $200{ }^{\circ} \mathrm{C}$ for $1 \mathrm{~min}$, cooled to RT at 
$50{ }^{\circ} \mathrm{C} \mathrm{min}^{-1}$, held for $1 \mathrm{~min}$ then re-heating as aforementioned. The crytallinity of the nanocomposites was calculated as described in the literature $[19,28]$, using a melting enthalpy of $100 \%$ crystalline PLLA of $93.7 \mathrm{~J} \mathrm{~g}^{-1}$, and corrected for the amount of PLLA present. The only difference being that in order to determine the crystallinity for the fibres for the first heating curve induced by melt-spinning, the entropy of cold crystallisation was subtracted from the melting enthalpy. The crystallinity for the second heating curve was calculated using the method in [28]. Single fibre tensile tests were conducted to determine the mechanical properties of the fibres. Fibres were carefully mounted on card sample holders and bonded between further sections of card using epoxy resin (Araldite Rapide), to give a gauge length of $20 \mathrm{~mm}$. As aforementioned, a section $\sim 10 \mathrm{~mm}$ in length was taken from each fibre in the post bonded region away from the test specimen for SEM analysis and diameter determination. Tensile tests were conducted at $21{ }^{\circ} \mathrm{C}$ with a crosshead speed of $15 \mu \mathrm{m}$ $\mathrm{s}^{-1}$, according to BS ISO 11566:1996 using a TST 350 tensile testing rig (Linkam Scientific Instrument Ltd.) equipped with a $20 \mathrm{~N}$ load cell. The gauge length was 20 $\mathrm{mm}$. The displacement and load were recorded and converted to stress and strain, based on the actual fibre diameters determined via SEM/image analysis prior to testing. The modulus, ultimate tensile strength (UTS), strain at UTS, break tenacity, and strain at break were then calculated.

\subsection{Fabrication of UD PLLA/PDLLA composites}

The fabrication process of UD PLLA/PDLLA composites is shown schematically in Fig. 1. Fibres of amorphous PDLLA and semi-crystalline PLLA (with or without $\mathrm{BC} / \mathrm{CNCs}$ ) were melt spun directly on top of one another onto the take-up spool of the fibre spinning rig (described in 2.5), in a layer-by-layer approach, utilising different controlled pitches, to ensure that a PLLA fibre volume fraction to PDLLA of 0.6 was maintained. These spools containing the two PLA fibres were then taken for compression moulding to produce consolidated, aligned PLLA fibre reinforced PDLLA composites. The first layer was PDLLA/PDLLA +7 wt.\% CNC in order to provide matrix during subsequent compression moulding to the reinforcing PLLA/composite fibres. This process continued sequentially until a total of 5 alternating compositions had been deposited on the spool. The cardboard spools with the layered composites on their outside were wrapped with PTFE release film and 
compression moulded at $150^{\circ} \mathrm{C}$ (below the melt point of PLLA, yet well above the $\mathrm{T}_{g}$ of PDLLA) with a force of $15 \mathrm{kN}$ for $5 \mathrm{~min}$, this resulted in the tubular spool being squashed flat, concomitantly allowing the fibres to maintain their alignment and yield flat composite samples. In order to improve consolidation of this material, composite specimens were cut, stacked, and wrapped in polyimide film and tape for confinement, then pressed further in a brass mould to produce samples for dynamic mechanical analysis (DMA) (tensile and 3-point bending modes) as well as tensile testing. Specimens measured $4 \mathrm{~mm}$ width $\times 0.5 \mathrm{~mm}$ thick, with spans $20 \mathrm{~mm}$ for DMA and $50 \mathrm{~mm}$ for tensile testing, with a gauge length of $30 \mathrm{~mm}$. Specimens were produced to allow assessment of fibre dominant and matrix dominant properties by testing in the direction of the unidirectional fibres and transverse to them. All UD composites, composite and monolithic samples produced are summarised in Table 1.

\subsection{Viscoelastic and static mechanical properties of the composites}

The viscoelastic behaviour of the nanocomposites was characterised using DMA (Tritec 2000, Triton Technology Ltd., Keyworth, UK). DMA was performed in both three-point bending and tensile modes. The storage modulus, loss modulus and energy dissipation factor $(\tan \delta)$ were measured from $30^{\circ} \mathrm{C}$ to $120^{\circ} \mathrm{C}$ using a heating rate of 5 ${ }^{\circ} \mathrm{C} \min ^{-1} 1$ at a frequency of $1 \mathrm{~Hz}$. Tensile tests were conducted in accordance with BS EN ISO 527: 1996 using an Instron universal material testing machine (Instron 4502, Instron Corporation, MA, USA) equipped with a $1 \mathrm{kN}$ load cell. Samples were tested at $1 \mathrm{~mm} \mathrm{~min}^{-1}$.

\section{Results and discussion}

3.1 Physical and thermal properties of PLA fibres

Neat PLA fibres exhibited a smooth morphology (Fig. 2a) the addition of BC/CNC acted to increase the rugosity of the fibres (Fig. 2b-e). The diameter of the fibres increased concomitantly with cellulose content due to increase in the melt viscosity at constant winding speeds (see Table 2). Neat PLLA fibres and PLLA fibres filled with 2 wt.\% $\mathrm{C}_{6}$-BC exhibited the highest draw ratios, 44.4 and $46.7 \%$, respectively. Draw ratios were substantially reduced for PLA fibres containing 7 wt. $\% \mathrm{CNC}$, to $17.2 \%$. The reduced draw ratio for hexanoic modified $\mathrm{BC}\left(\mathrm{C}_{6}-\mathrm{BC}\right)$ is indicative of improved compatibility with PLLA, over unmodified $\mathrm{BC}$ or $\mathrm{C}_{12}-\mathrm{BC}$, as demonstrated in our previous work on monolithic BC/PLA composites [28]. In our work we used a freeze- 
drying approach to produce the extrusion and melt-spinning masterbatch in order to prevent $\mathrm{BC}$ hornification.

First and second heating traces for neat PLLA and 2 wt.\% BC (modified and unmodified) - filled PLLA are shown in Fig. 3, with key data $\left(T_{g}, T_{m}, T_{c}\right.$ and percentage crystallinity, $\chi_{c}$ ) summarised in Table 3 . There is no significant difference between the samples in terms of $T_{g}$ and $T_{m}$. However, the onset crystallisation temperature on second heating is clearly reduced in the presence of $\mathrm{BC}$. This is due to $\mathrm{BC} / \mathrm{CNC}$ acting as nucleation sites for crystal growth, as previously reported for monolithic samples [16-19]. Melting $\left(T_{c}\right)$ occurred at $90.9{ }^{\circ} \mathrm{C}$ for PLLA filled with 7 wt.\% CNC, compared to neat PLLA at $109.2{ }^{\circ} \mathrm{C}$ (in second heating). PLLA fibres possess a crystallinty of $45.6 \%$ (based on $1^{\text {st }}$ heating), representing strain or orientation induced crystallinity, whereas PLLA filled with 7 wt.\% CNCs posses crystallinity of $34.0 \%$. Similarly, lower $T_{c}$ values are evident for the $2 \mathrm{wt} . \% \mathrm{BC}$ filled fibres compared to neat PLLA. These lower $\left(T_{c}\right)$ values are explained by the reduced drawing ratio reducing the orientation-induced crystallization; the presence of the cellulose increased the viscosity of the polymer melt resulting in larger diameter fibres. On the second heating however, PLLA and 7 wt.\% CNC/PDLLA possessed crystallinities of $43.4 \%$ and $51.1 \%$, respectively. This is further evidence that the CNCs act as effective sites for crystal nucleation and growth. PLA/CNC fibres (filled with 1-3 wt.\% CNW) were reported to have crystallinities of $16-18 \%$ [15], the lower crystallinities reported in their work are due to the lower draw ratio they used, of 2 , resulting in fibres $90-95 \mu \mathrm{m}$ diameter.

The single fibre tensile properties are summarised in Table 2 and representative stress-strain curves shown in Fig. 4. The tensile strength and modulus for all fibre types are proximal. Neat PLLA fibres exhibited the highest modulus of $6.06 \mathrm{GPa}$ due to spinning induced chain orientation and higher draw ratios compared to the other fibre types. This enhanced crystallinity masked the effects of the $\mathrm{BC} / \mathrm{CNC}$ fibre reinforcement in terms of single fibre mechanical properties. PLLA fibres filled with 2 wt.\% $\mathrm{C}_{6}$-BC exhibited the highest yield strength of all fibres, $141 \mathrm{MPa}$, in comparison to neat PLLA at $127 \mathrm{MPa}$ (Table 2). $\mathrm{C}_{6}$-modified $\mathrm{BC}$ has been shown to result in improved tensile strengths for monolithic samples in our previous work [28], due to enhanced compatibility with PLA. All fibres exhibit strain-hardening, with 
strains to failure well above monolithic PLA (typically 2-4\%), $26 \%$ for neat PLLA, and $150 \%$ for PLLA filled with 2 wt. $\%$ BC, respectively. Strain-to-failure of the fibres increased concomitantly with increased starting fibre diameter (lower draw ratio). Strain-hardening was more evident for neat PLA and PLLA filled with 2 wt.\% $\mathrm{C}_{6}$-BC. These fibres experienced the highest draw ratios (Table 2) and exhibited the highest crytallinities due to orientation (first heating curve, Table 3 ). It is also evident that fibres of lower orientation induced crystallinity and larger starting diameters exhibited higher strains to failure (Table 2). Neat amorphous PLA samples exhibited the highest break tenacity, of $208 \mathrm{MPa}$, with neat PLLA and $\mathrm{C}_{6}$-BC filled PLLA having proximal values of $182 \mathrm{MPa}$ and $170 \mathrm{MPa}$, respectively. Previously reported PLA/CNW-loaded fibres (at 1-3 wt.\%) exhibited far lower moduli of 2.5-2.7 GPa, and strengths of 49-56 $\mathrm{MPa}$ [15], our improved performance is due to higher draw ratio and higher induced crystallinity within the fibres.

3.2 Physical and viscoelastic properties of unidirectional self-reinforced PLA composites

Composites reinforced with unidirectional PLLA or PLLA/CNC fibres exhibited greatly enhanced storage moduli both in bending and in tension over neat PLA, as shown in Figs. 5a-d. For comparison, the storage moduli of all samples at $20{ }^{\circ} \mathrm{C}$ are given in Table 4. Those filled with CNC, in both matrix and in the UD fibres exhibited storage moduli at $20{ }^{\circ} \mathrm{C}$ of $11.6 \mathrm{GPa}$ (bending), $7.0 \mathrm{GPa}$ (tension), compared to neat PLA at 4.2 (bending) and $2.8 \mathrm{GPa}$ (tension). UD self-reinforced PLA without CNC also exhibited an enhanced storage modulus at $6.8 \mathrm{GPa}$ (bending) and 4.9 GPa (tension). These improvements are due to i) the significant strainorientation induced crystal alignment in PLLA and PLLA/CNC fibres, and ii) the presence of the $\mathrm{CNC}$ reinforcing phase present both in the fibres and the matrix. Furthermore, the storage modulus remained markedly higher than monolithic PLA at temperatures above $T_{g}$ to $120^{\circ} \mathrm{C}$ (Figs. 5a and 5c). This production route enables $\mathrm{CNCs}$ to be incorporated into amorphous PLA matrix phases at an amount known to form a percolating network (at 6 vol. \% $\mathrm{CNC}$, equivalent to $7 \mathrm{wt} . \% \mathrm{CNC}$ ) that is itself reinforced by PLLA fibres themselves containing $7 \mathrm{wt} . \% \mathrm{CNC}$ with fibre mechanical properties enhanced by strain-induced chain orientation and PLA crystal alignment due to drawing. Contrary to our previous findings based on monolithic PLLA composites filled with $\mathrm{C}_{6}-\mathrm{BC}$ and $\mathrm{C}_{12}$ - $\mathrm{BC}$ [28], we observed a significant reduction in 
the $\tan \delta$ peak in the presence of 7 wt.\% CNC, as well as UD PLLA fibres in amorphous PDLLA-based matrices. The loading fraction of $\mathrm{CNC}$, at percolated network threshold and strain-induced chain orientation in neat PLLA fibres evidently had a profound impact on the mobility of the polymer chains, as shown in Figs. 5b and 5d. Habibi et al. [33], produced CNC-g-PDLA composites, and at $10 \% \mathrm{CNC}$ the storage modulus reported was $4.15 \mathrm{GPa}$ at $25{ }^{\circ} \mathrm{C}$. Here we measured storage moduli up to $6.69 \mathrm{GPa}$ at $20{ }^{\circ} \mathrm{C}$ in tension for the composites filled with $7 \mathrm{wt} . \% \mathrm{CNC}$, in both matrix and in the UD fibres.

Static tensile testing of self-reinforced PLA revealed significant improvements in modulus and strength due to the presence of UD PLLA fibres and CNC in both the PLLA fibres and PDLLA matrix, of $123 \%$ and $35 \%$ when compared against the neat PDLLA matrix, respectively (Table 5). Most interestingly the strain to failure of UD fibre self-reinforced PLA was increased to $17.1 \%$ (no cellulose present), a $185 \%$ improvement in the strain to failure of PDLLA, which is due to drawing of the PLLA fibres, as shown for single fibre tensile tests (Fig. 4). Whilst the presence of CNC acted to improve the modulus and strength, the strain-to-failure was low in comparison to those filled with UD PLLA fibres, this is due to the percolating network in the matrix, impeding chain movement in the PDLLA. Samples tested with UD fibres perpendicular to test direction exhibited lower properties than neat the PDLLA matrix, which seem to suggest poor fibre/matrix adhesion and/or consolidation is required. To our knowledge there are no examples of such selfreinforced UD PLA/nanocellulose composites, and very few on melt processed monolithic PLA/nanocellulose composites with nanocellulose loadings of $>5 \mathrm{wt} . \%$. In other work, PLLA composites filled with 5 wt.\% $\mathrm{C}_{6}$-modified cellulose achieved a Young's modulus of $1.63 \mathrm{MPa}$ [28]. Martínez-Sanz reported that 5 wt.\% poly(glycidylmethacrylate)-grafted CNC reinforced PLLA has a Young's modulus of 2.61 $\mathrm{GPa}$ and tensile strength of $49 \mathrm{MPa}$ [34]. Both these values are significantly lower than the moduli reported here.

Whilst the work here focused on self-reinforced PLA/BC in amorphous PLA as matrix, this technique could potentially be applied to produce self-reinforced UD PLA composites with a higher performance using stereo-complex PLA as the matrix for the fibre/composite reinforcement phase. The melt point of stereo-complex PLA is 
significantly higher than PLLA or PDLA, depending on composition, at circa $230^{\circ} \mathrm{C}$ [35], giving a suitable processing window of circa $50^{\circ} \mathrm{C}$ for the production of selfreinforced PLA composites.

\section{Conclusions}

PLA fibres filled with $\mathrm{BC}$ and $\mathrm{CNC}$, melt-spun at the same speed $\left(100 \mathrm{~m} \mathrm{~min}^{-1}\right)$ exhibited reduced draw ratios, in comparison with those spun using neat PLA. Surface-only modification of BC with hexanoic acid, acted to improve the draw ratio (at $2 \mathrm{wt} . \% \mathrm{C}_{6}$-BC loading in PLLA). Whilst the nanocellulose acted as a nucleation agent for PLA crystal growth, the effect of the filler on composite behaviour is masked by the effect of strain-induced chain orientation during melt-spinning. Strain induced chain orientation due to melt spinning resulted in PLLA fibres with enhanced modulus and strength, the incorporation of $2 \mathrm{wt} \% \mathrm{C}_{6}$-BC into PLA resulted in moderate strength improvement. Filling the PLA above the percolating network threshold of $\mathrm{CNC}$ by extrusion followed by melt-spinning resulted in even lower draw ratios, whilst these fibres had lower mechanical properties, their strain to failure significantly increased over fibres filled with 2 wt.\% BC and neat PLA fibres. Furthermore we reported a route to produce UD PLLA/CNC fibre reinforced PDLLA, with or without $\mathrm{CNCs}$ at percolating thresholds $(7 \mathrm{wt} . \% \mathrm{CNC})$ via controlled layerby-layer filament winding and subsequent consolidation. Consolidation was conducted at temperatures sufficient to allow the PDLLA/CNC matrix to flow, wetting the PLLA/CNC composite fibres. We observed improvements in viscoelastic properties of up to $175 \%$ in terms of storage modulus in bending. Furthermore strains to failure for PLLA fibre reinforced PDLLA were recorded to be as high as $17 \%$. This processing route is adaptable for other thermoplastic polymers, and is extendible to stereo-complex PLA reinforced semi-crystalline matrices, with applications at higher temperatures than amorphous PLA.

\section{Acknowledgements}

The authors would like to thank the UK Engineering and Physical Science Research Council (EPSRC) for funding JJB (EP/E007538/1) and KYL (EP/F032005/1) and the UK Technology Strategy Board (TP BD068B). We also greatly appreciate the University of Vienna for continued the support for KYL. 


\section{References}

[1] B. Eling, S. Gogolewski, A.J. Pennings, Polymer, 23 (1982) 1587-1593.

[2] S.D. Incardona, L. Fambri, C. Migliaresi, Journal of Materials Science: Materials in Medicine, 7 (1996) 387-391.

[3] K. Mezghani, J.E. Spruiell, Journal of Polymer Science, Part B: Polymer Physics, 36 (1998) 1005-1012.

[4] X. Yuan, A.F.T. Mak, K.W. Kwok, B.K.O. Yung, K. Yao, Journal of Applied Polymer Science, 81 (2001) 251-260.

[5] J.A. Cicero, J.R. Dorgan, Journal of Polymers and the Environment, 9 (2001) 110.

[6] L. Fambri, A. Pegoretti, R. Fenner, S.D. Incardona, C. Migliaresi, Polymer, 38 (1997), 79-85.

[7] N.J. Capiati, R.S. Porter, Journal of Materials Science, 10 (1975) 1671-1677.

[8] R. Li, D. Yao, Journal of Applied Polymer Science, 107 (2008) 2909-2916.

[9] W. Jia, R.H. Gong, C. Soutis, P.J. Hogg, Plastics, Rubber and Composites, 4 (2014) 83-88.

[10] I.-H. Kim, S. Lee, Y. Jeong, Fibers Polymers, 10 (2009) 687-693.

[11] J.A. Cicero, J.R. Dorgan, J. Jazen, J. Garrett, J. Runt, J.S. Lin, Journal of Applied Polymer Science, 86 (2002) 2828-2838.

[12] J.A. Cicero, J.R. Dorgan, J. Garrett, J. Runt, J.S. Lin, Journal of Applied Polymer Science, 86 (2002) 2839-2846.

[13] S. Solarski, M. Ferreira, E. Devaux, G. Fontaine, P. Bachelet, S. Bourbigot, R. Delobel, P. Coszach, M. Murariu, A.D.S. Ferreira, M. Alexandre, P. Degee, P. Dubois, Journal of Applied Polymer Science, 109 (2008) 841.

[14] P. Pötschke, T. Andres, T. Villmow, S. Pegel, H. Brünig, K. Kobashi, Composites Science and Technology, 70 (2010) 343.

[15] M.J. John, R. Anandjiwala, K. Oksman, A.P. Mathew, Journal of Applied Polymer Science, 127 (2013) 274-281.

[16] J.J. Blaker, K.-Y. Lee, A. Bismarck, Journal of Biobased Materials and Bioenergy, 51 (2011) 1-16.

[17] D. Wu, L. Wu, B. Xu, Y. Zhang, M. Zhang, Journal of Polymer Science, Part B: Polymer Physics, 45 (2007) 1100.

[18] A. Pei, Q. Zhou, L.A. Berglund, Composites Science and Technology, 70 (2010) 815. 
[19] A.P. Mathew, K. Oksman, M. Sain, Journal of Applied Polymer Science, 101 (2006) 300-310.

[20] M. Iguchi, S. Yamanaka, A. Budhiono, Journal of Material Science, 35 (2000) 261-270.

[21] K.Y. Lee, G. Buldum, A. Mantalaris, A. Bismarck, Macromolecular Bioscience, 14 (2014) 10-32.

[22] K-Y. Lee, T. Tammelin, K. Schulfter, H. Kiiskinen, J. Samela, A. Bismarck, Applied Materials and Interfaces, 4 (2012) 4078-4086.

[23] W. Czaja, D. Romanovicz, R.M. Brown, Cellulose, 11 (2004) 403-411.

[24] Y.C. Hsieh, H. Yano, M. Nogi, S.J. Eichhorn, Cellulose, 15 (2008) 507-513.

[25] T. Saito, R. Kuramae, J. Wohlert, L.A. Berglund, A. Isogai, Biomacromolecules, 14 (2013) 248-253.

[26] K.M. Zakir Hossain, M.S. Hasan, D. Boyd, C.D. Rudd, I. Ahmed, W. Thielemans, Biomacromolecules, 15 (2014) 1498-1506.

[27] D. Liu, X. Yuan, D.J. Bhattacharya, Journal of Materials Science, 47 (2012) 3159.

[28] K.-Y. Lee, J.J. Blaker, A. Bismarck, Compos. Sci. Technol., 69 (2009) 2724 2733.

[29] H. Toyosaki, T. Naritomi, A. Seto, M. Matsuoka, T. Tsuchida, F. Yoshinaga, Bioscience Biotechnology and Biochemistry, 59 (1995) 1498-1502.

[30] J.J. Blaker, K.Y. Lee, X.X. Li, A. Menner, A. Bismarck, Green Chem., 11 (2009) 1321-1326.

[31] M. Roman, W.T. Winter, Biomacromolecules, 5 (2004) 1671-1677.

[32] J.J. Blaker, J.C. Knowles, R.M. Day, Acta Biomaterialia, 4 (2008) 264-272.

[33] Y. Habibi, S. Aouadi, J-M. Raquez, P. Dubois, Cellulose, 20 (2013) 2877-2885.

[34] M. Martínez-Sanz, M.A. Abdelwahab, A. Lopez-Rubio, J.M. Lagaron, E. Chiellini, T.G. Williams, D.F. Wood, W.J. Orts, S.H. Imam, European Polymer Journal, 49 (2013) 2062-2072.

[35] M. Kakuta, M. Hirata, Y. Kimura, Journal of Macromolecular Science, Part C: Polymer Reviews, 49 (2009) 107-140. 


\section{FIGURES AND TABLES}

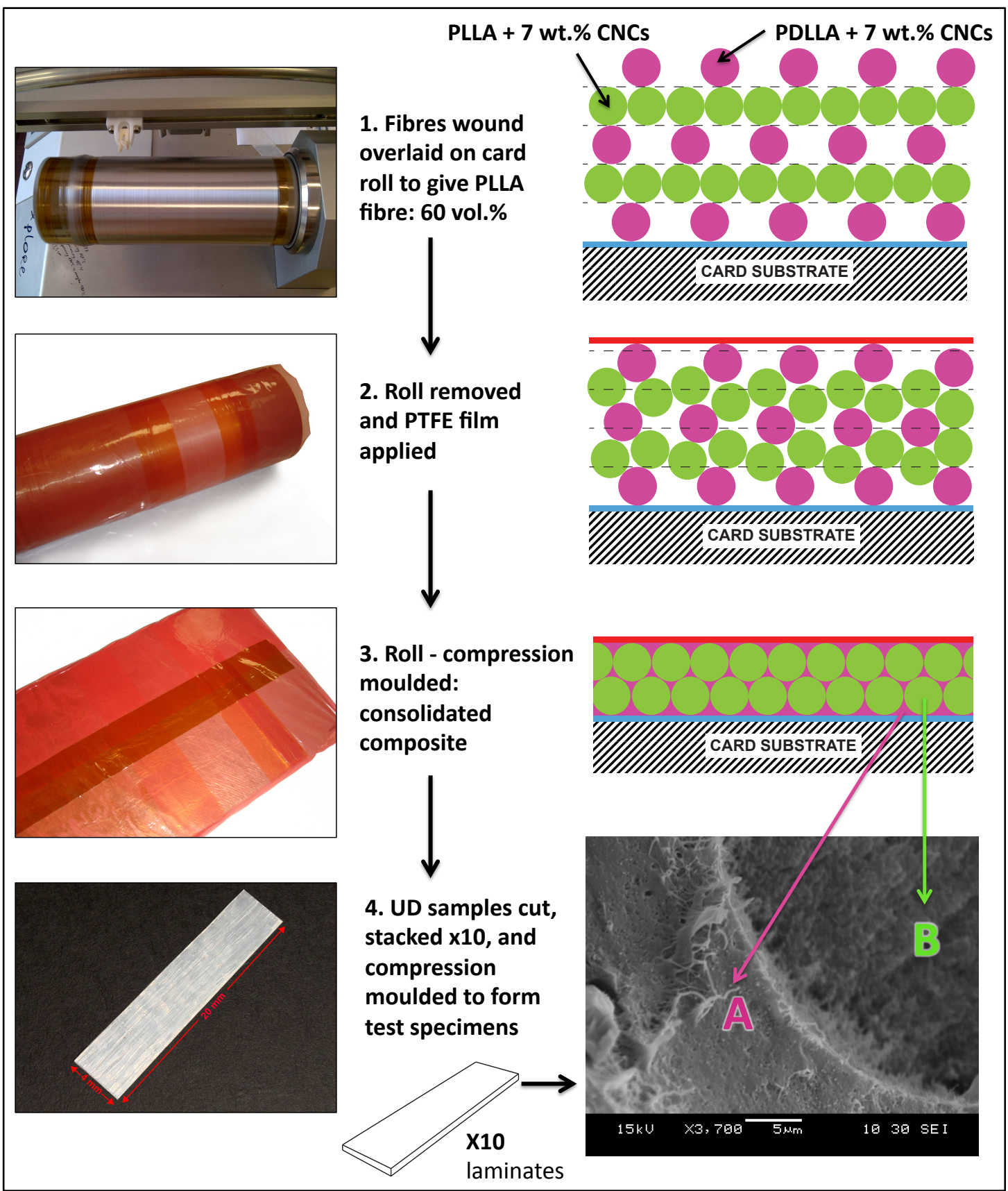

Fig. 1. Schematic of the filament winding based production method for UD selfreinforced PLA composites. Letter (A) in the SEM image represents the PDLLA matrix filled with CNC, and (B) the PLLA fibre filled with CNC. 


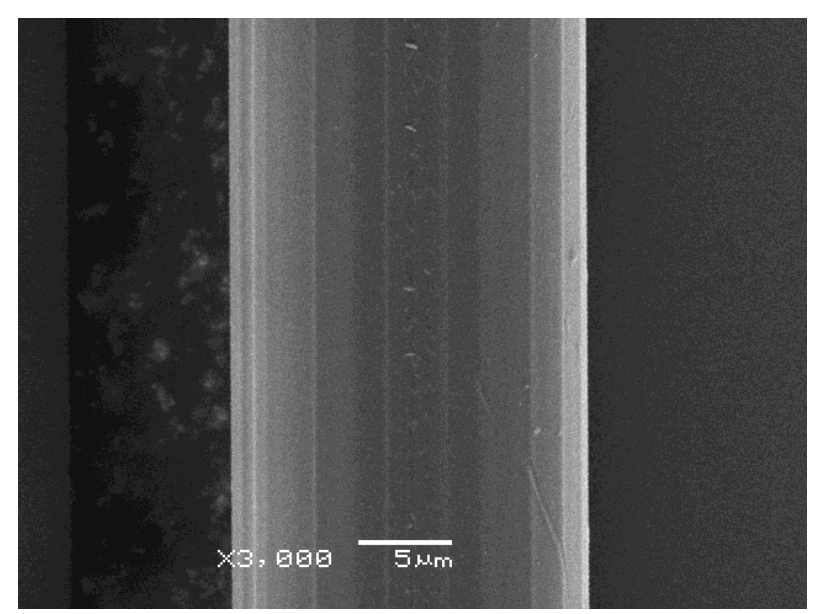

Fig. 2a.

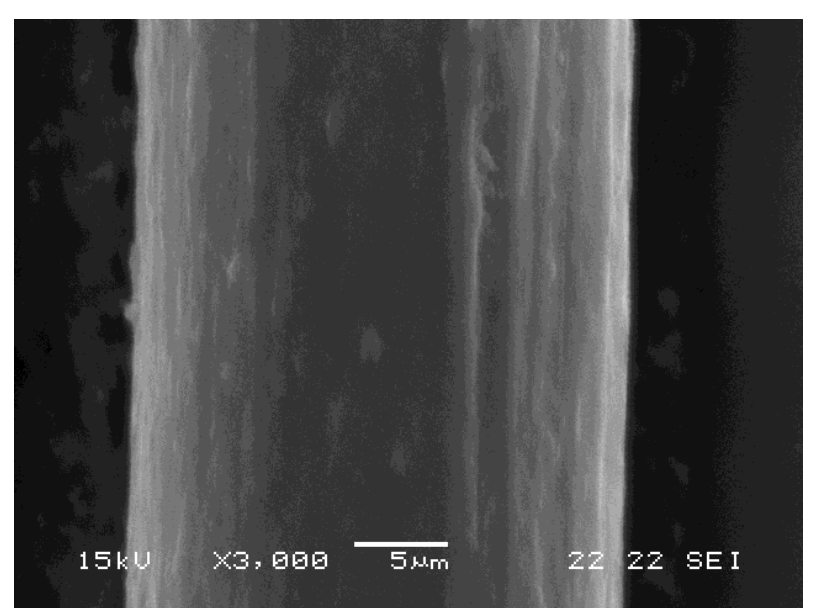

Fig. 2b.

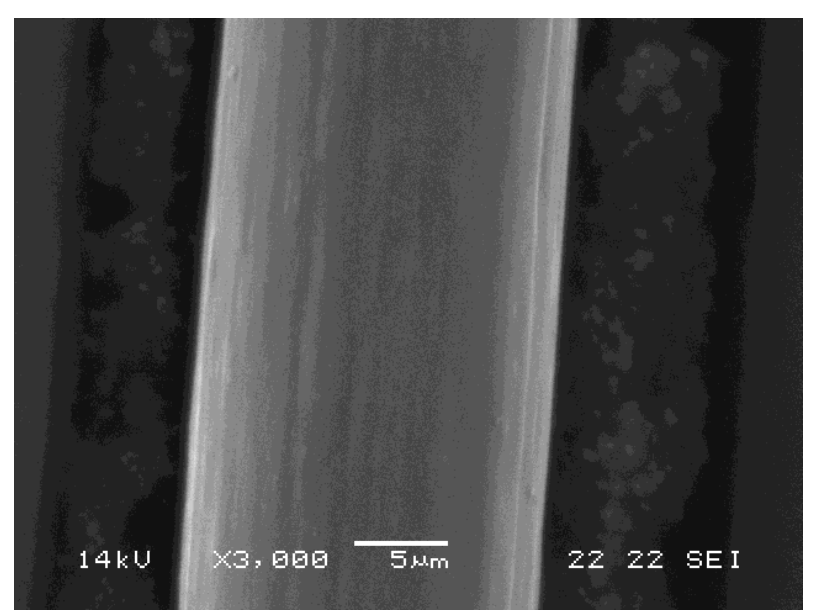

Fig. 2c. 
Fig. 2d.

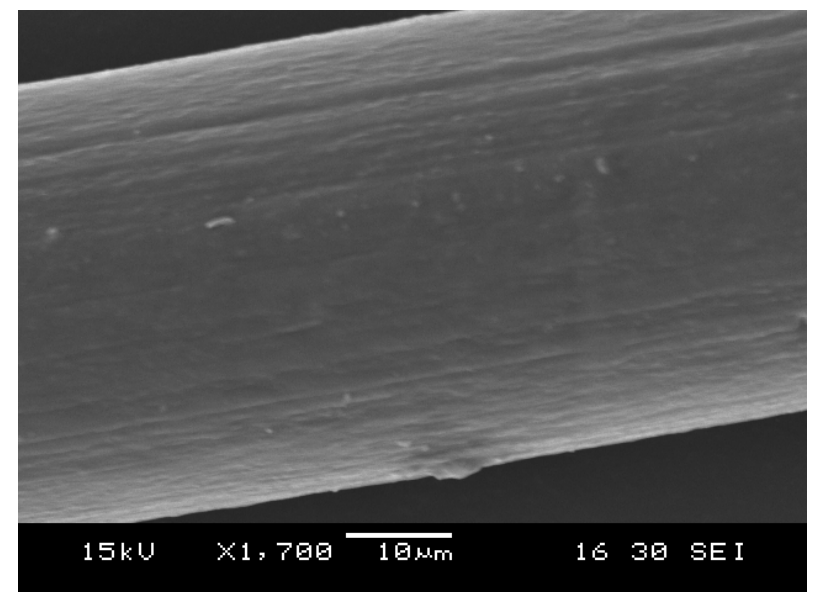

Fig. 2e.

Fig. 2. SEM images of (a) neat PLLA fibre, (b) PLLA + 2 wt. $\%$ BC, (c) PLLA +2 wt. $\% \mathrm{C}_{6}$-BC, (d) PLLA +2 wt. $\% \mathrm{C}_{12}$-BC, and (e) PLLA +7 wt. $\%$ CNC. 


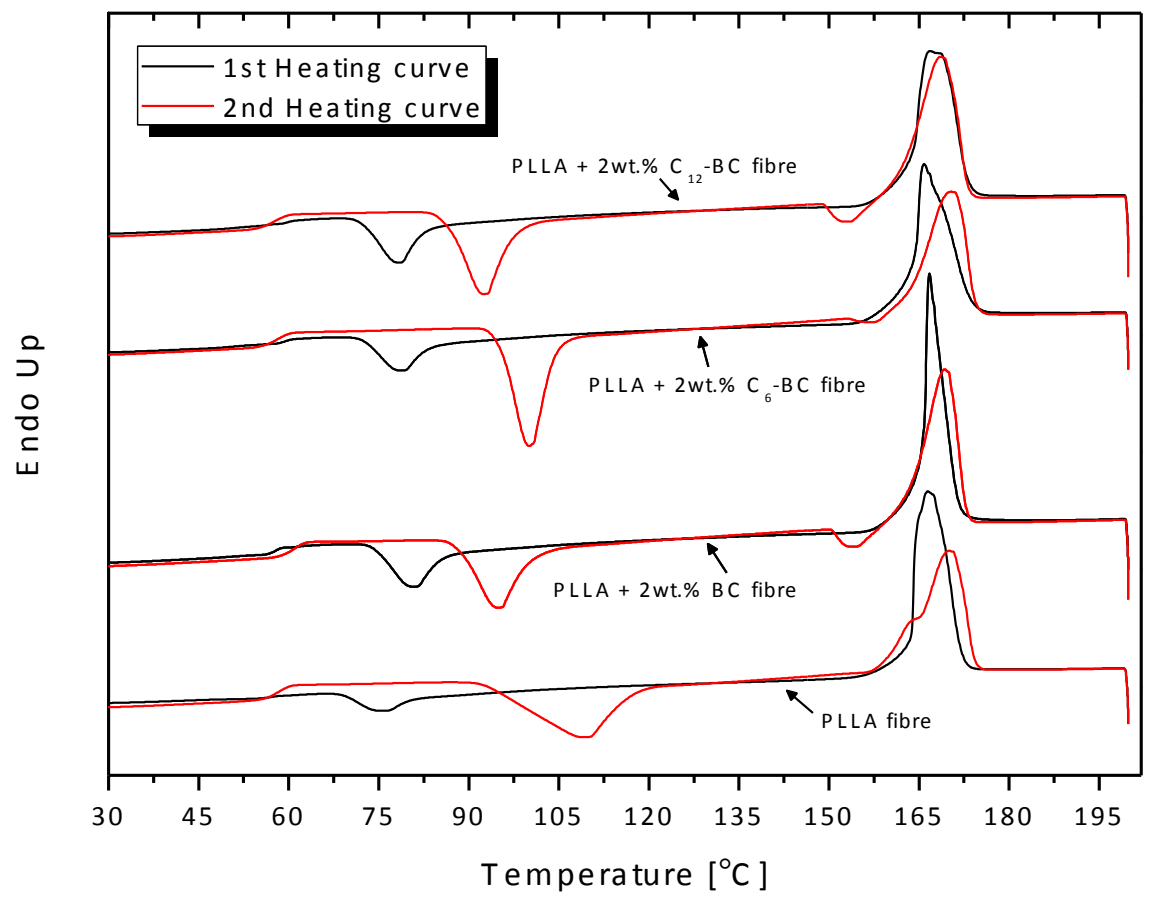

Fig. 3. First and second heating DSC profiles comparing addition of $2 \mathrm{wt} . \%$ modified and unmodified $\mathrm{BC}$ on neat PLLA (melt-spun fibres).

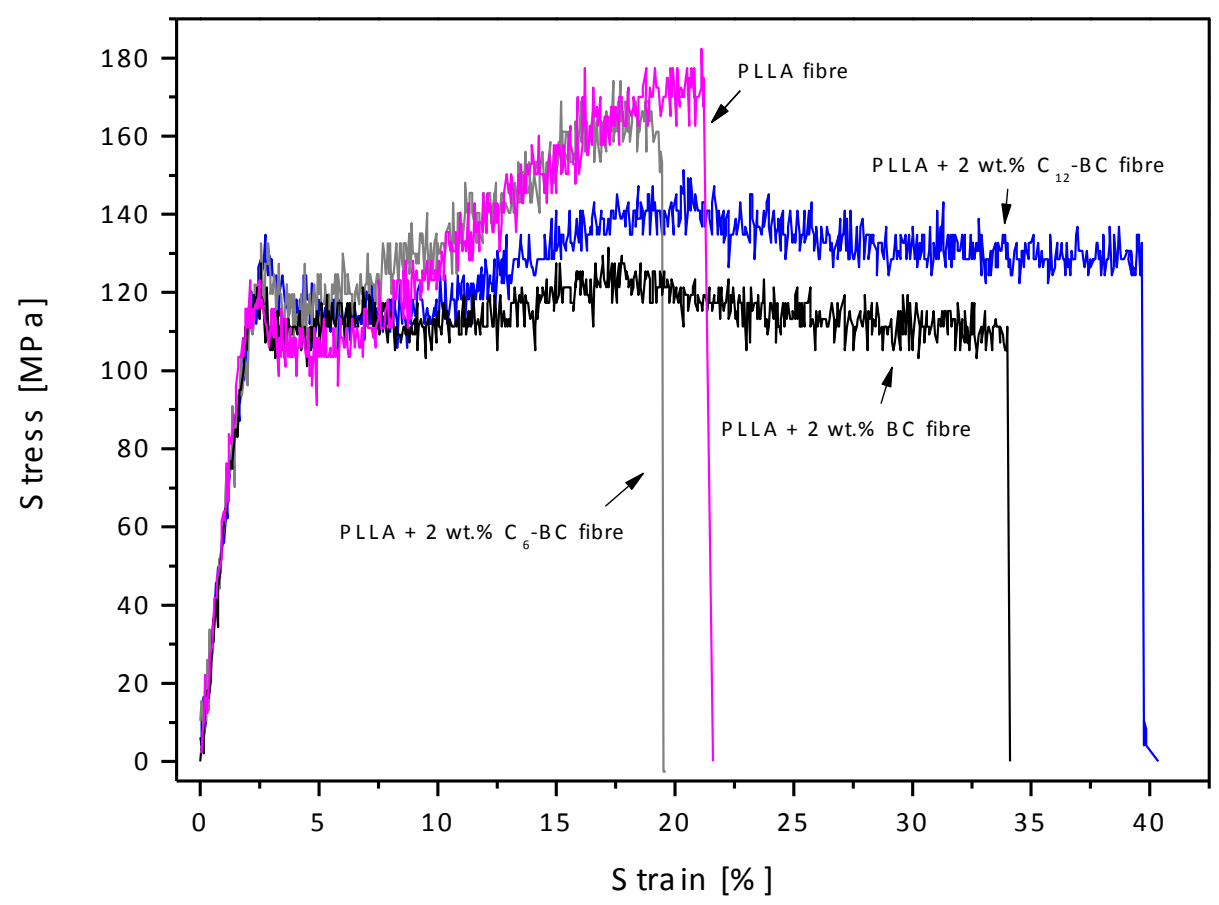

Fig. 4. Representative stress-strain profiles from single fibres tested in tension. 


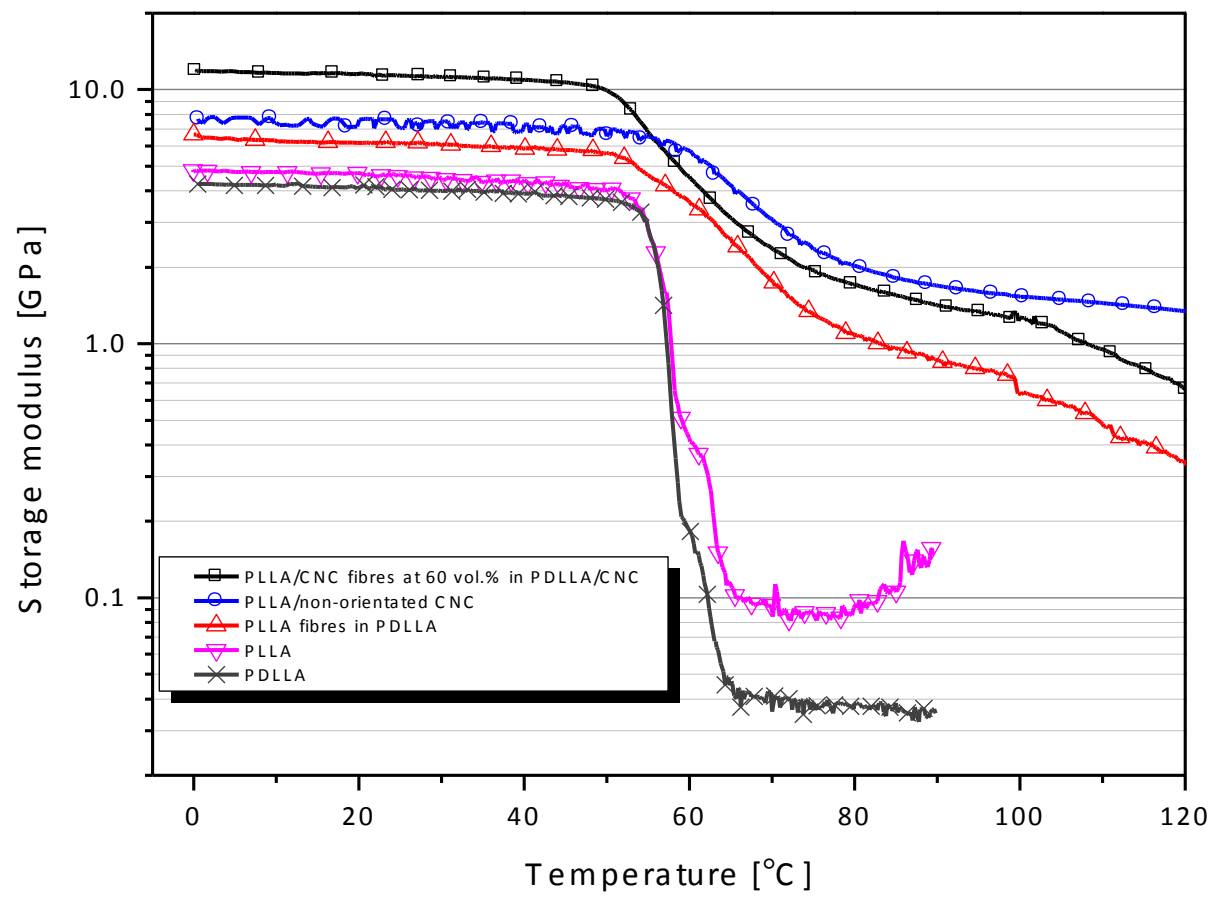

Fig. 5a. Storage modulus of the PLLA fibre reinforced PDLLA composites and monoliths, measured in three-point bending.

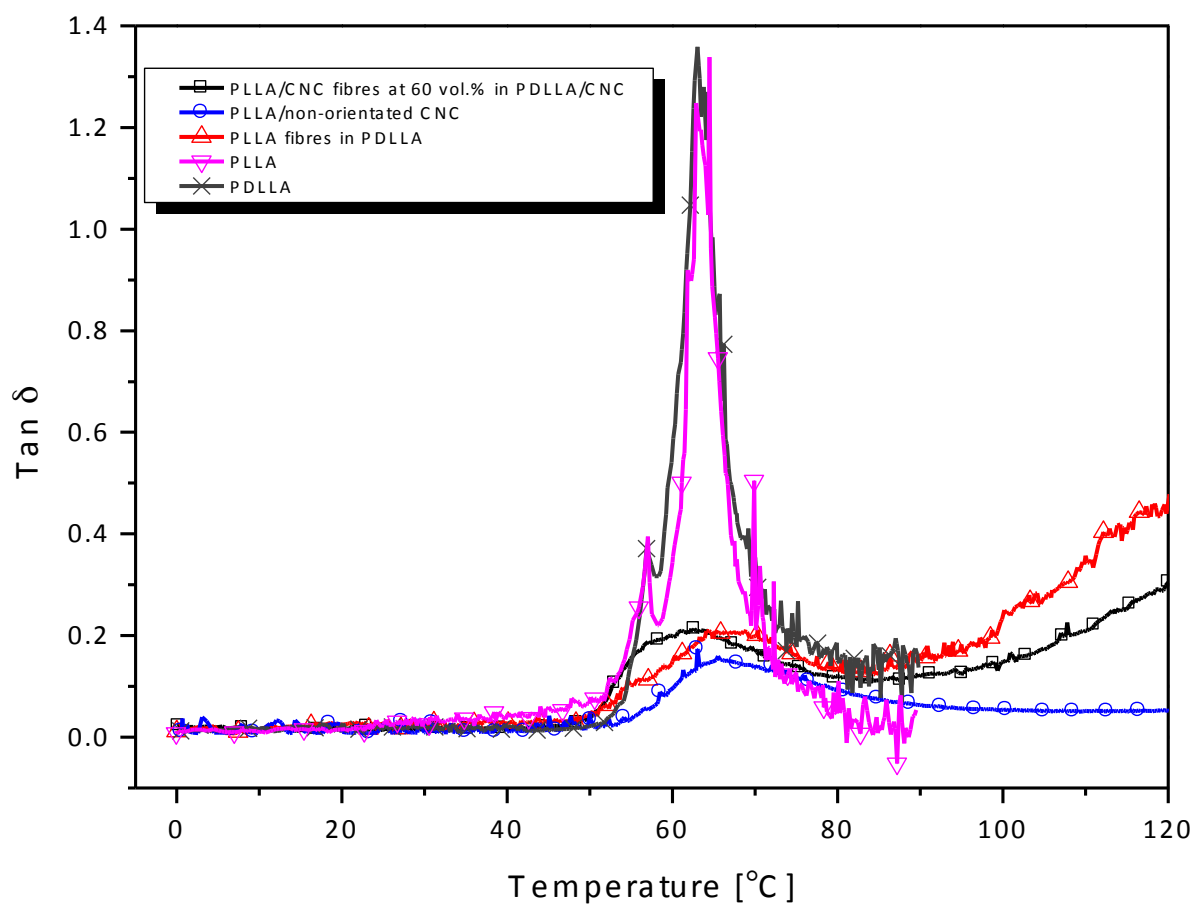

Fig. 5b. Loss factor tan $\delta$ of the PLLA fibre reinforced PDLLA composites and monoliths, measured in three-point bending. 


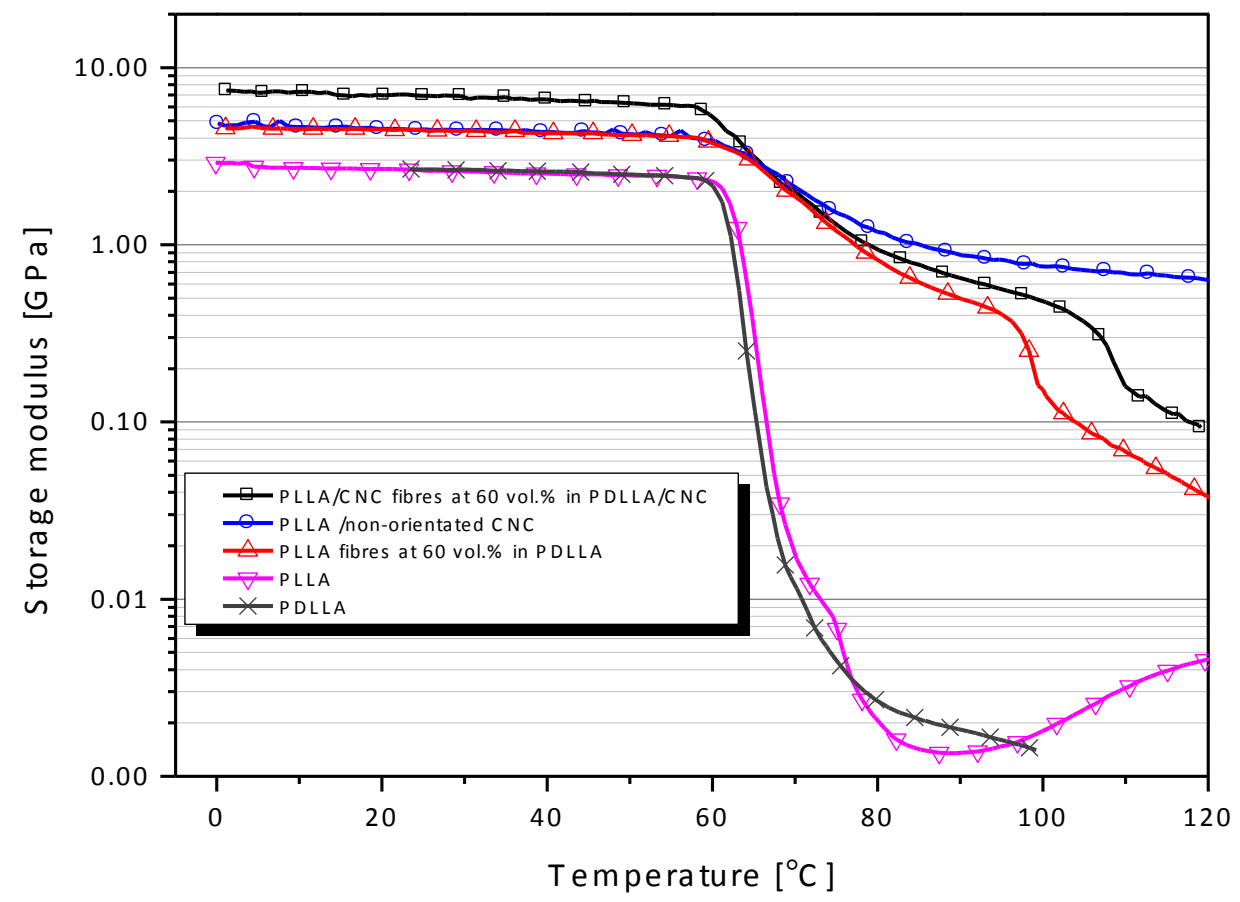

Fig. 5c. Storage modulus of the PLLA fibre reinforced PDLLA composites and monoliths, measured in tension.

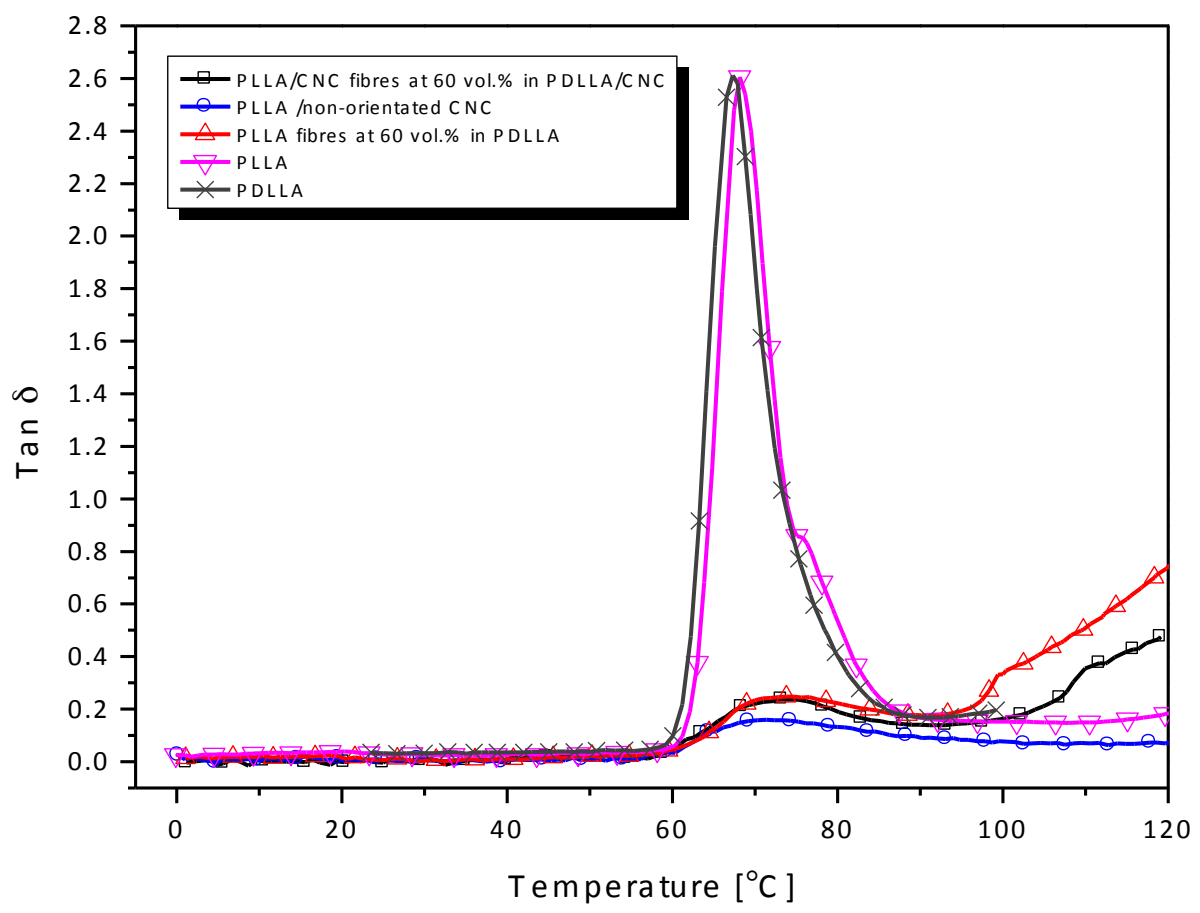

Fig. 5d. Loss factor tan $\delta$ of the PLLA fibre reinforced PDLLA composites and monoliths, measured in tension. 


\section{TABLES:}

Table 1. Overview of samples produced.

\begin{tabular}{|c|c|}
\hline $\begin{array}{l}\text { Composite fibres and } \\
\text { monolithic fibres }\end{array}$ & UD composite, composite and monolithic samples produced \\
\hline $\begin{array}{l}\text { Neat PDLLA } \\
\text { Neat PLLA } \\
\text { PLLA }+2 \text { wt. } \% \text { BC } \\
\text { PLLA }+2 \text { wt. } \% \mathrm{C}_{6} \text {-BC } \\
\text { PLLA }+2 \text { wt. } \% \mathrm{C}_{12}-\mathrm{BC} \\
\text { PLLA }+7 \text { wt. } \% \text { CNC } \\
\text { PDLLA }+7 \text { wt. } \% \text { CNC }\end{array}$ & $\begin{array}{l}\text { Neat PDLLA monolith } \\
\text { Neat PLLA monolith } \\
\text { "UD PLLA fibres at } 60 \text { vol. } \% \text { in PDLLA matrix } \\
\text { 'UD 'PLLA + } 7 \text { wt. } \% \text { CNC' fibres at } 60 \text { vol. } \% \text { in 'PDLLA + 7wt. } \% \text { CNC' matrix } \\
\text { PLLA + } 7 \text { wt. } \% \text { CNC } \\
\text { PDLLA + } 7 \text { wt. } \% \text { CNC }\end{array}$ \\
\hline
\end{tabular}

Note that $\mathrm{C}_{6}$ - $\mathrm{BC}$ and $\mathrm{C}_{12}$ - $\mathrm{BC}$, denote hexanoic acid and dodecanoic acid modified bacterial cellulose, respectively; ${ }^{*} \mathrm{UD}$ composites tested at $0^{\circ}$ and $90^{\circ}$ degrees to fibre direction.

Table 2. Mechanical properties and initial fibre diameters for single fibres tested in tension.

\begin{tabular}{|c|c|c|c|c|c|c|c|}
\hline Fibre sample & $\begin{array}{l}\text { Modulus } \\
\text { [GPa] }\end{array}$ & $\begin{array}{l}\text { UTS } \\
\text { [MPa] }\end{array}$ & $\begin{array}{c}\text { Strain } \\
\text { at UTS } \\
{[\%]}\end{array}$ & $\begin{array}{c}\text { Break } \\
\text { tenacity } \\
\text { [MPa] }\end{array}$ & $\begin{array}{l}\text { Strain at } \\
\text { break [\%] }\end{array}$ & $\begin{array}{c}\text { Fibre } \\
\text { dia. } \\
{[\mu \mathrm{m}]}\end{array}$ & $\begin{array}{l}\text { Draw } \\
\text { ratio }\end{array}$ \\
\hline PDLLA & $\begin{array}{c}5.20 \\
\text { SD } 0.4\end{array}$ & $\begin{array}{c}115 \\
\text { SD } 10\end{array}$ & $\begin{array}{c}2.8 \\
\text { SD } 0.2\end{array}$ & $\begin{array}{l}208 \\
\text { SD } 7\end{array}$ & $\begin{array}{c}41.0 \\
\text { SD } 16.0\end{array}$ & $\begin{array}{c}30.7 \\
\text { SD } 1.5\end{array}$ & 32.6 \\
\hline PLLA & $\begin{array}{l}6.06 \\
\text { SD } 1.5\end{array}$ & $\begin{array}{c}127 \\
\text { SD } 28\end{array}$ & $\begin{array}{c}2.7 \\
\text { SD } 0.5\end{array}$ & $\begin{array}{c}182 \\
\text { SD } 38\end{array}$ & $\begin{array}{c}26.1 \\
\text { SD } 3.2\end{array}$ & $\begin{array}{l}22.5 \\
\text { SD } 1.7\end{array}$ & 44.4 \\
\hline $\begin{array}{l}\text { PDLLA + } 2 \text { wt. } \% \\
\text { BC }\end{array}$ & $\begin{array}{c}4.15 \\
\text { SD } 0.6\end{array}$ & $\begin{array}{c}112 \\
\text { SD } 9\end{array}$ & $\begin{array}{c}2.9 \\
\text { SD } 0.3\end{array}$ & $\begin{array}{c}138 \\
\text { SD } 18\end{array}$ & $\begin{array}{c}150 \\
\text { SD } 43\end{array}$ & $\begin{array}{c}34.5 \\
\text { SD } 2.1\end{array}$ & 29.0 \\
\hline $\begin{array}{l}\text { PLLA + } 2 \text { wt. } \% \\
\text { BC }\end{array}$ & $\begin{array}{c}5.87 \\
\text { SD } 0.6\end{array}$ & $\begin{array}{c}123 \\
\text { SD } 12\end{array}$ & $\begin{array}{c}2.5 \\
\text { SD } 0.2\end{array}$ & $\begin{array}{c}114 \\
\text { SD } 14\end{array}$ & $\begin{array}{c}36.6 \\
\text { SD } 17.6\end{array}$ & $\begin{array}{c}25.0 \\
\text { SD } 1.1\end{array}$ & 40.0 \\
\hline $\begin{array}{l}\text { PLLA + } 2 \text { wt. } \% \\
\mathrm{C}_{6}-\mathrm{BC}\end{array}$ & $\begin{array}{c}5.73 \\
\text { SD } 0.6\end{array}$ & $\begin{array}{c}141 \\
\text { SD } 11\end{array}$ & $\begin{array}{c}3.0 \\
\text { SD } 0.2\end{array}$ & $\begin{array}{c}170 \\
\text { SD } 18\end{array}$ & $\begin{array}{c}17.0 \\
\text { SD } 3.0\end{array}$ & $\begin{array}{c}21.4 \\
\text { SD } 1.2\end{array}$ & 46.7 \\
\hline $\begin{array}{l}\text { PLLA + } 2 \text { wt. } \% \\
\mathrm{C}_{12}-\mathrm{BC}\end{array}$ & $\begin{array}{c}5.72 \\
\text { SD } 0.3\end{array}$ & $\begin{array}{c}123 \\
\text { SD } 6\end{array}$ & $\begin{array}{c}2.7 \\
\text { SD } 0.2\end{array}$ & $\begin{array}{c}120 \\
\text { SD } 9\end{array}$ & $\begin{array}{c}38.4 \\
\text { SD } 15.4\end{array}$ & $\begin{array}{c}26.1 \\
\text { SD } 1.1\end{array}$ & 38.3 \\
\hline $\begin{array}{l}\text { PLLA + } 7 \text { wt. } \% \\
\text { CNC }\end{array}$ & $\begin{array}{c}3.35 \\
\text { SD } 0.6\end{array}$ & $\begin{array}{c}70 \\
\text { SD } 13\end{array}$ & $\begin{array}{c}2.4 \\
\text { SD } 0.4\end{array}$ & $\begin{array}{c}110 \\
\text { SD } 44\end{array}$ & $\begin{array}{c}158.4 \\
\text { SD } 14.3\end{array}$ & $\begin{array}{c}58.0 \\
\text { SD } 6.7\end{array}$ & 17.2 \\
\hline $\begin{array}{l}\text { PDLLA + } 7 \text { wt. } \% \\
\text { CNC }\end{array}$ & $\begin{array}{c}3.08 \\
\text { SD } 0.5\end{array}$ & $\begin{array}{c}58 \\
\text { SD } 7\end{array}$ & $\begin{array}{c}2.1 \\
\text { SD } 0.3\end{array}$ & $\begin{array}{c}93 \\
\text { SD } 8\end{array}$ & $\begin{array}{c}83.0 \\
\text { SD } 9.2\end{array}$ & $\begin{array}{c}40.1 \\
\text { SD } 1.9\end{array}$ & 24.9 \\
\hline
\end{tabular}

Table 3. Thermal properties assessed via DSC for melt-spun fibres. Where, $T_{g}, T_{m}, T_{c}$ and $\chi_{c}$ are glass transition temperature, melting temperature, temperature of cold crystalisation, and percentage crystallinity, respectively.

\begin{tabular}{lccccc} 
Fibre sample & $\begin{array}{c}\text { Heating } \\
\text { curve }\end{array}$ & $\begin{array}{c}T_{g} \\
{\left[{ }^{\circ} \mathrm{C}\right]}\end{array}$ & $\begin{array}{c}T_{c} \\
{\left[{ }^{\circ} \mathrm{C}\right]}\end{array}$ & $\begin{array}{c}T_{m} \\
{\left[{ }^{\circ} \mathrm{C}\right]}\end{array}$ & $\begin{array}{c}\chi_{c} \\
{[\%]}\end{array}$ \\
\hline PLLA & $1^{\text {st }}$ & 57.1 & 75.0 & 166.4 & 45.6 \\
\hline
\end{tabular}




\begin{tabular}{lccccc}
\cline { 2 - 5 } & $2^{\text {nd }}$ & 58.2 & 109.2 & 169.9 & 43.4 \\
\hline $\begin{array}{l}\text { PLLA + 2 wt.\% } \\
\text { BC }\end{array}$ & $1^{\text {st }}$ & 57.8 & 80.5 & 166.7 & 34.4 \\
\cline { 2 - 5 } & $2^{\text {nd }}$ & 60.8 & 94.7 & 169.2 & 44.2 \\
\hline PLLA + 2 wt.\% & $1^{\text {st }}$ & 59.5 & 78.3 & 165.8 & 36.9 \\
\cline { 2 - 6 } C6 $_{6}$ BC & $2^{\text {nd }}$ & 58.0 & 99.9 & 170.2 & 41.4 \\
\hline $\begin{array}{l}\text { PLLA + 2 wt.\% } \\
\text { C } 12-B C\end{array}$ & $1^{\text {st }}$ & 59.9 & 78.1 & 166.8 & 36.6 \\
\cline { 2 - 6 } & $2^{\text {nd }}$ & 57.6 & 92.4 & 168.6 & 46.6 \\
\hline $\begin{array}{l}\text { PLLA + 7 wt.\% } \\
\text { CNC }\end{array}$ & $1^{\text {st }}$ & 57.1 & 81.2 & 167.6 & 34.0 \\
\cline { 2 - 6 } & $2^{\text {nd }}$ & 59.4 & 90.9 & 167.5 & 51.1 \\
\hline
\end{tabular}

Table 4. Storage modulus in bending and tension measured at $20{ }^{\circ} \mathrm{C}$ for fibre reinforced composites and monoliths.

\begin{tabular}{lcc}
\hline Sample & $\begin{array}{c}\text { Storage } \\
\text { modulus in } \\
\text { bending [GPa] }\end{array}$ & $\begin{array}{c}\text { Storage } \\
\text { modulus in } \\
\text { tension [GPa] }\end{array}$ \\
\hline Neat PLLA & 4.20 SD 0.6 & 2.76 SD 0.2 \\
Neat PDLLA & 4.14 SD 0.4 & 2.83 SD 0.2 \\
PLLA/Non-Orientated CNC & 7.00 SD 0.6 & 4.63 SD 0.3 \\
PDLLA/Non-Orientated CNC & 3.89 SD 0.3 & 2.79 SD 0.6 \\
PLLA fibres $\left(0^{\circ}\right)$ in PDLLA & 6.81 SD 0.6 & 4.87 SD 0.6 \\
PLLA fibres $\left(90^{\circ}\right)$ in PDLLA & 4.73 SD 0.2 & 2.64 SD 0.3 \\
PLLA/CNC fibres at 60 vol.\% in PDLLA/CNC & 11.55 SD 0.5 & 6.96 SD 0.6 \\
\hline
\end{tabular}

Table 5. Tensile properties of monolithic PDLLA and UD PLLA and PLLA/CNC in amorphous PDLLA and PDLLA/CNC reinforced matrices, where $\mathrm{E}_{\mathrm{T}}$ is tensile modulus, $\sigma$ UTS is ultimate tensile strength, $\sigma$ is failure strength, $\varepsilon$ yield is yield strain, and $\varepsilon$ represents strain at break.

\begin{tabular}{lccccc}
\hline Sample & $\mathrm{E}_{\mathrm{T}}[\mathrm{GPa}]$ & $\sigma$ UTS $[\mathrm{MPa}]$ & $\sigma_{\mathrm{T}}[\mathrm{MPa}]$ & $\varepsilon$ yield [\%] & $\varepsilon$ [\%] \\
\hline Neat PDLLA & 2.52 & 48.4 & 44.0 & 2.7 & 6.0 \\
& $\mathrm{SD} 0.06$ & $\mathrm{SD} 2.5$ & $\mathrm{SD} 1.0$ & $\mathrm{SD} 0.2$ & SD 2.0 \\
\hline PLLA fibres $\left(0^{\circ}\right)$ in PDLLA & 3.65 & 65.6 & 59.9 & 2.9 & 17.1 \\
& SD 0.18 & SD 2.5 & SD 2.2 & SD 0.1 & SD 9.9 \\
\hline
\end{tabular}




\begin{tabular}{lccccc}
\hline PLLA fibres $\left(90^{\circ}\right)$ in PDLLA & 2.39 & - & 12.9 & 0.6 & 0.6 \\
& SD 0.06 & & SD 1.2 & SD 0.1 & SD 0.1 \\
\hline PLLA/CNC fibres $\left(0^{\circ}\right)$ at 60 & 3.75 & 53.7 & 52.5 & 2.0 & 2.1 \\
vol.\% in PDLLA/CNC & SD 0.09 & SD 3.7 & SD 3.5 & SD 0.4 & SD 0.5 \\
\hline PLLA/CNC fibres $\left(90^{\circ}\right)$ at & 2.67 & - & 13.4 & 0.5 & 0.5 \\
60 vol.\% in PDLLA/CNC & SD 0.11 & & SD 4.4 & SD 0.2 & SD 0.2 \\
\hline
\end{tabular}

